\title{
From superliquidus to solidification: Determining the rheology of magmatic dikes
}

\author{
L.A. FISCHER* $*$, C. GIEHL, S². SPÜRGIN, \\ B. JOACHIM-MROSKO \\ - Albert-Ludwigs-University Freiburg, Germany \\ (*correspondence: \\ lennart.fischer@minpet.uni-freiburg.de) \\ - Anton Paar Germany GmbH, Germany \\ ${ }^{3}$ Hans G. Hauri KG Mineralstoffwerke, Bötzingen, Germany \\ ${ }^{4}$ University of Innsbruck, Austria
}

During cooling crystallizing silicate liquids continuously undergo rheological changes. These are commonly marked by the onset of crystallization, increasing crystallinity and thus increasing viscosity. The extent of these changes is strongly dependent on the cooling rate but also on flow velocity of the melt (e.g. the shear rate). This is more pronounced in intrusive systems where fast solidification is expected and flow-induced crystallization might occur.

In this study a phonolite-hosted essexite dike from Fohberg (Kaiserstuhl Volcanic Complex, SW Germany) was investigated. Such silica-undersaturated tephritic dikes are known from volcanic complexes and originate from fractionation of high-alkaline basaltic melts or low degree $(<10 \%)$ partial melting of upper mantle rocks. Their high alkaline and low silica content leads to relatively low melt viscosities compared to other mafic melts.

Viscosity was determined using an Anton Paar hightemperature rotational rheometer (FRS 1800) enabling continuous assessment of the rheology from superliquidus conditions to complete solidification of the melt. The powdered sample was first heated to $1500{ }^{\circ} \mathrm{C}$ and then cooled down until solidification with cooling rates of 2 and $5 \mathrm{~K} / \mathrm{min}$ and shear rates of $5 \mathrm{~s}^{-1}, 1 \mathrm{~s}^{\mathrm{s}}$ (both in rotational mode) and in oscillatory mode to exclude shear-induced effects.

Above liquidus temperatures all experimental melts show newtonian behavior and increasing viscosity with decreasing temperature. The onset of crystallization is marked by a strong and sharp increase in viscosity. This point of first crystallization strongly depends on the applied shear rate. Higher shear rates lead to earlier (at higher temperature) crystallization $\left(5 \mathrm{~s}^{-}: \mathrm{T}=1190{ }^{\circ} \mathrm{C}, 1 \mathrm{~s}^{-\bullet}: \mathrm{T}=111{ }^{\circ} \mathrm{C}\right)$. Moreover, faster cooling rates delay the onset of crystallization to lower temperatures $\left(2 \mathrm{~K} / \mathrm{min}\right.$ : $\mathrm{T}=1190{ }^{\circ} \mathrm{C}$, $5 \mathrm{~K} / \mathrm{min}: \mathrm{T}=1085{ }^{\circ} \mathrm{C}$ ). The experiment performed in oscillatory mode lacks a sudden viscosity increase as observed in rotational experiments, but crystallization can be observed at temperatures below $1060^{\circ} \mathrm{C}$. 